\author{
Yaba Addiction in Bangladesh-A Crisis Corroding our Future \\ Jamal $M^{1}$, Kiyoshi Ameno $K^{2}$, Tanaka $N^{3}$, Ito $A^{4}$, Takakura $A^{5}$, Kinoshita $H^{6}$
}

Bangladesh Journal of Medical Science Vol. 15 No. 04 October'16.

\section{The facts}

It is heartbreaking that the young talents of Bangladesh are being hooked on drugs like yaba, phensedyl. In recent years, the number of yaba addicts has risen dramatically. Yaba is a highly addictive mix of methamphetamine and caffeine, mostly in tablet form, taken orally or inhaled after being melted. It creates an intense hallucinogenic effect which can enable users to stay awake for days on end due to flooding the brain with dopamine. When the drug begins to wear off, brain function slowly shift back to normal as the dopamine overload recedes. This can make users repeat yaba use again and again to try and get the same pleasure as before. That is the point at which we can say a person is physically dependent on the drug which may lead to often frighting withdrawal symptoms including depression and suicidal thoughts when the yaba is withdrawn.

Students, entertainment industry people and upscale youths are the most common victims who face the unprecedented allure to engage in yaba ${ }^{1}$. Unemployment often leads to frustration which may lead to or may contribute to the usage of yaba. Two major factors accelerate access to abuse drugs among users in Bangladesh: one is the presence of illicit drug-dealing groups, who indiscriminately offer drugs to people, and the other is new technology such as the internet and mobile phones. The exact prevalence of yaba users in Bangladesh is hard to say, but seizures of the drug are frequent thus raising alarm over the increase of yaba use.

\section{The truth about yaba}

Seeing that the lung, liver and brain are the primary organ of methamphetamine accumulation ${ }^{2}$. Chronic methamphetamine use leads to the major damage to nearly every system of the body, most notably the lung, liver, heart, kidney and brain ${ }^{3}$. Caffeine, the most widely consumed psychoactive substance in the world, acts as a CNS stimulant but can potentiate the toxic effects of methamphetamine ${ }^{4}$. Thus, methamphetamine and caffeine together is a recipe for disaster and sometimes lethal, without warning. Yaba abusers are also a threat because they are often involved in violent crimes ${ }^{5}$.

\section{The strategies}

Given the extent of drug abuse in Bangladesh, there are still very limited options for treatment and rehabilitation throughout the country. However, professional detox facilities of internationally accepted standards are to be strongly recommended. Although we are accustomed to thinking about preventive interventions for youth, it is clearly necessary to consider how we can prevent drug abuse in our society. Through education and rehabilitation, we can turn the tide of drug abuse and addiction. Strict law enforcement, intensive public awareness and prevention activities are indispensable in protecting them from drug abuse. Finally, what is particularly important at the grassroots level is to change the thinking about their drug addiction, to it being thought of "as a disease, not a crime".

1. Mostofa Jamal, Assistant Professor, Department of Forensic Medicine, Faculty of Medicine, Kagawa University, 1750-1, Ikenobe, Miki, Kita, Kagawa 761-0793, Japan

2. Kyoshi Ameno, Associate Professor

3. Naoko Tanaka, Assistant Professor

4. Asuka Ito,

5. Ayaka Takakura

6. Hiroshi Kinoshita, Professor, Department of Forensic MedicineFaculty of Medicine, Kagawa University

Corresponds to: Mostofa Jamal, Assistant Professor, Department of Forensic Medicine Faculty of Medicine, Kagawa University, 1750-1, Ikenobe, Miki, Kita, Kagawa 761-0793, Japan, E-mail: jamal@kms.ac.jp 


\section{Reference}

1. Chowdhury ST. Yaba, the 'Madness Drug', Is Finding New Routes Into Bangladesh. 12 Feb, 2015, Vice News.

2. Volkow ND, Fowler JS, Wang GJ, Shumay E, Telang F, Thanos PK, Alexoff D. Distribution and Pharmacokinetics of Methamphetamine in the Human Body: Clinical Implications. PLoS One 2010; 5 (12):e15269.

3. Mooney LJ, Glasner-Edwards S, Rawson RA, Ling W. Medical effects of methamphetamine use. In:
Roll JM, Rawson RA, Ling W, Shoptaw S, editors. In Methamphetamine Addiction: From Basic Science to Treatment, New York, Guilford, 2009: 117-142.

4. Sinchai T, Plasen S, Sanvarinda Y, Jaisin Y, Govitrapong P, Morales NP, Ratanachamnong P, Plasen D. Caffeine potentiates methamphetamine-induced toxicity both in vitro and in vivo. Neurosci Lett 2011; 502 (1):65-69.

5. Momin SM. The yaba epidemic in Bangladesh. $13 \mathrm{Sep}$, 2015, The Independent. 